\title{
In Memoriam, H. W. Florey: an Episode
}

With the sudden death of Lord Florey at the age of 69 on 21 February 1968 the Society lost a very distinguished original member. Among the lay public he is chiefly known for the work which led to the demonstration of the therapeutic powers of penicillin, 12 years after its discovery by Fleming. The 'golden age of antibiotics' thus initiated is reflected by the fact that whereas isolated papers on microbial antagonism had appeared scattered through the literature during the previous 50 years, no less than $15 \%$ of the papers appearing in our journal during the first 5 years of its existence (1947-52) dealt wholly or largely with antibiotics.

Florey's achievements were, of course, great in other fields; his other scientific work, for example; or the training in experimental methods applied to broad pathological problems which so many young workers received in his department and disseminated all over the world; or his fruitful presidency of the Royal Society (1960-65); or the key part he played in the founding of the Australian National University and in particular the John Curtin School of Medical Research. These and other achievements have been chronicled elsewhere (e.g. E. P. Abraham, 1970) and it may be appropriate in a journal such as ours to pay respect to his memory by singling out his microbiological work, and in particular to attempt to describe in more intimate detail the work on penicillin carried out in his department at the beginning of World War II.

A carefully checked scientific account of this early work is to be found in chapter 15 of the monograph on antibiotics written by Florey and colleagues (Florey et al. 1949) and in some little-known but informative papers in volume 6 of the Journal of the History of Medicine, 1951. Naturally, no hint was permitted in any publication from Florey's department of the crucial part he played in encouraging and inspiring his colleagues, in directing the project so effectively and unobtrusively, or in the clear-cut elegance of his own laboratory work.

Florey's interest in naturally-occurring antibacterial substances goes back to the I920s. In a joint paper with N. E. Goldsworthy (1930), a variety of bacteria were shown to produce diffusible substances which inhibited the growth of other bacteria, and the comment was made that the phenomenon was well known. The paper was concerned with the occurrence of lysozyme in the secretions and mucosa of the intestinal tract of various animals, and Florey continued to work on lysozyme, first with Dr Marjory Stephenson at Cambridge-very briefly-then with Mrs S. T. Harrison at Sheffield. When he moved to the Sir William Dunn School of Pathology at Oxford as professor in 1935 the work was pursued; lysozyme was purified by E. A. H. Roberts, and its substrate was characterized and mode of action investigated by E. B. Chain and L. A. Epstein.

Florey and Chain decided that it would be of interest to examine some of the other naturally-occurring antibacterial substances which had been described, including those formed by Pseudomonas pyocyanea (aeruginosa), Bacillus brevis and Penicillium notatum which, it so happened, was among the Dunn School cultures. A few preliminary experiments with the penicillium were made by Chain and Epstein in 1938/39 with results 


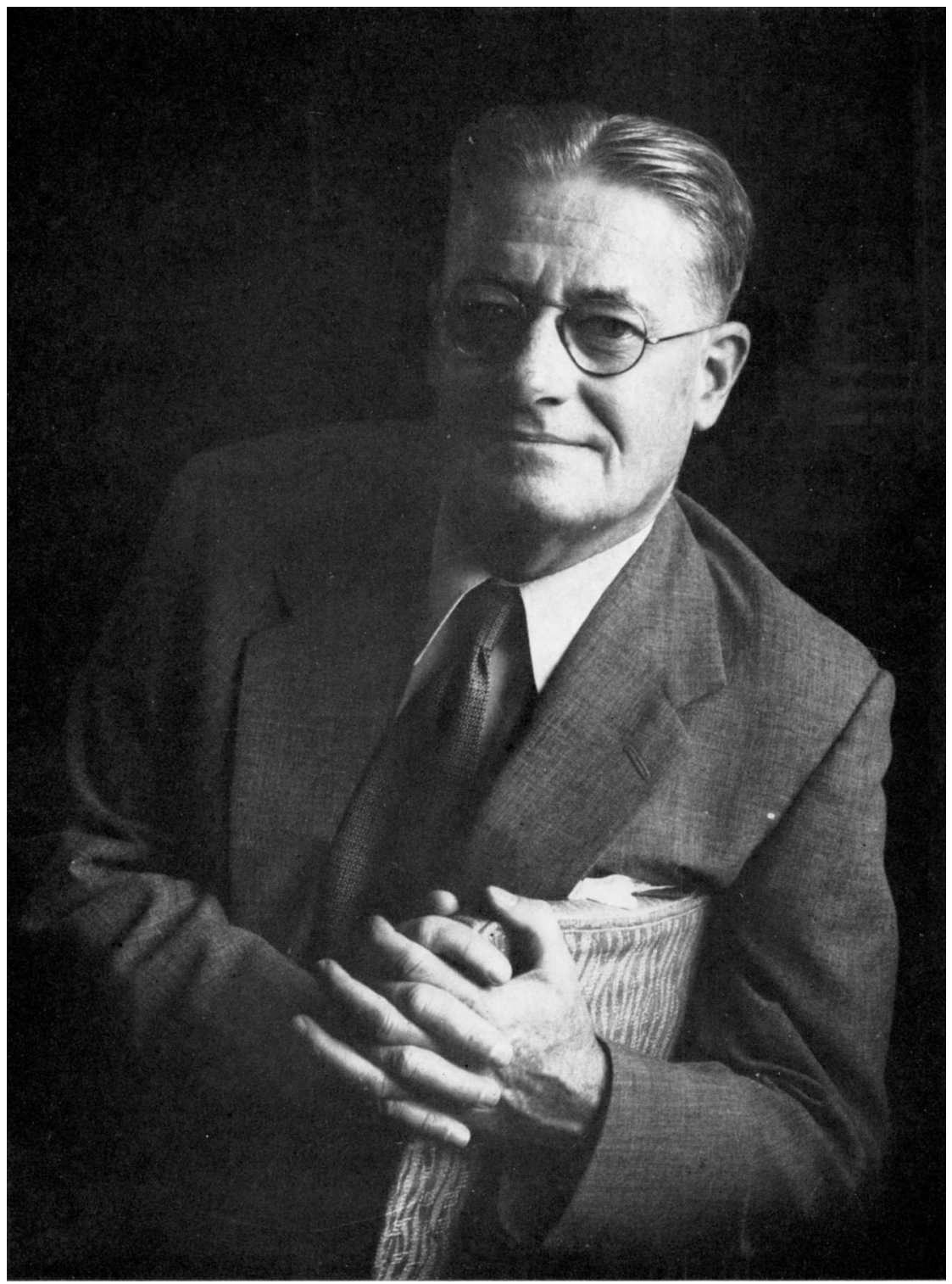

LORD FLOREY, O.M. M.B. PH.D. F.R.S. I 898-I968

Honorary member of the Society for General Microbiology 
described by the latter as 'not impressive' (Falk, I944), but in October 1939 more sustained work began when Florey engaged a full-time junior research worker, N. G. Heatley, to assist him personally. Heatley's first day's work, on 2 October 1939, was to drill holes in Petri dishes for the well type of assay described by Florey and Goldsworthy, which had the great merit that the solutions to be assayed did not need to be sterile. Heatley remained permanently at the Dunn School; his forte was improvization, a quality normally of little value to a research worker, though it proved useful under the wartime conditions of restriction and shortage.

In November 1939 Florey applied for and obtained from the Rockefeller Foundation a grant towards the investigation that he and Chain had planned.

During the winter of $1939 / 40$ several aspects of the penicillin problem were explored simultaneously. The cylinder-plate diffusion assay method, developed from Florey and Goldsworthy's well-plate, provided a simple means of assay with which bacterial contamination of the test solution did not, within limits, interfere. Until an arbitrary standard was adopted in March 1941, potency was expressed simply in terms of the diameter of the zone of inhibition, though in certain experiments internal standards were set up and calibration curves were made. Methods of propagating the fungus were tested, and it was grown on stationary shallow layers of the modified CzapekDox medium (containing glucose, sodium nitrate and other salts) used by Clutterbuck, Lovell \& Raistrick (1932). Correlations were sought between penicillin content of the medium and its $\mathrm{pH}$ and colour, and the colour, thickness, degree of corrugation and age of the mycelial mat. The characteristics of the penicillin-rich transpired droplets on the non-wetted upper surface of the mycelium were also recorded. The effect of different kinds of inocula and of variations in growth conditions such as temperature, age, surface/volume ratio, initial $\mathrm{pH}$ of medium and accessibility of air and carbon dioxide were semi-quantitatively examined, and various additions to the medium were tested, such as glutamine, glycerol, Marmite, peptone, malt extract, yeast extract, extra phosphate buffer, thioglycollic acid and meat extracts. Sabouraud's medium and one containing a peptic digest of horse or cow muscle, and the partial replacement of sodium by ammonium, or of glucose by sucrose or lactate, were also tried. No marked increase in penicillin yield followed from any of this or later work at Oxford; the one positive finding to emerge was the acceleration in rate of growth and penicillin production when a boiled extract of brewer's yeast was added (at the suggestion of Dr P. Fildes), such an extract being subsequently used as a routine.

It was found early in this phase of the work that, provided full aseptic precautions were taken, the medium harvested from under the mycelium could be replaced by fresh sterile medium and that about the same penicillin titre would be reached in two-thirds of the time needed by an ab initio culture. As many as 12 such serial replacements were done and much time was saved, both in the shortened incubation period and in the shorter time needed for sterilizing, cleaning and setting up of fresh cultures. The replacement technique was, however, abandoned about 2 years later when the frequency of contamination by a stubborn sporing air organism, despite regular use of a steam disinfectant-spray, made it unprofitable. None of the simplified media tried for replacement gave as good a yield as the Czapek-Dox+yeast-extract medium, though the concentration of the yeast extract could be decreased from $10 \%(\mathrm{v} / \mathrm{v})$ to 5 or even $2.5 \%$ without appreciably lowering the yield.

Meanwhile, experiments on extraction and purification were being carried out, 
mainly by Chain and by E. P. Abraham, who had joined the Dunn School in early January I940. The crude culture fluid was concentrated by vacuum distillation and later by freeze-drying, and classical separation procedures were tried, with limited success. A good method which was used commercially for several years was derived from the observations of Clutterbuck $e$ t al. (1932) that penicillin was completely removed from a watery solution at $\mathrm{pH} 2$ when shaken three times with ether, but was only partly removed at $\mathrm{pH} 7 \cdot \mathbf{2}$. No activity was recovered if the ether were evaporated alone, but if evaporated over water, the residual water contained a considerable proportion of the original activity. Thus penicillin passed more freely into ether at acid than at neutral $\mathrm{pH}$. It is curious that what now seems a fairly obvious deduction-that penicillin should be back-extractable from ether into neutral buffer-had not been made by Clutterbuck et al. (1932) and had only been conceived with difficulty at Oxford; indeed, one member of the group considered the deduction unsound.

The resulting solvent transfer extraction process, in which penicillin was extracted from the cooled acidified crude culture fluid by shaking with ether, and then taken from the separated ether phase back into water at neutral $\mathrm{pH}$, was not only simple but could be applied directly to unconcentrated culture fluid. It effectively freed penicillin from proteins, carbohydrates and salts, and enabled extracts to be simultaneously concentrated. There were, however, two minor difficulties: the first, loss of activity at low $\mathrm{pH}$, could be minimized by cooling the solutions; the second was the formation of troublesome emulsions in the primary extraction, and this could be overcome by centrifuging. Other solvents could be used in place of ether, such as isopropyl ether, chloroform and amyl acetate; the latter was soon used exclusively as it was less volatile, less inflammable, and far less of it was lost in solution in the spent culture fluid. Another minor improvement was to use phosphoric acid, which buffered at $\mathrm{pH} 2$ to 3 , unlike the hydrochloric acid used originally.

The production of concentrates by solvent transfer from the end of March 1940 opened the way to experiments in vivo by Florey and M. A. Jennings. At about the same time, A. D. Gardner, with the help of J. Orr-Ewing, began a long series of bacteriological studies, confirming and extending Fleming's observations, using the increasingly purified material. He also gave advice and assistance in the selection of strains of the pathogens used later in the mouse-protection experiments. Gardner made the interesting observation that penicillin in sublethal doses profoundly affected bacterial morphology; cocci were grossly swollen and rods were elongated, sometimes up to ten times their normal length (Gardner, 1940).

The brown powder obtained by lyophil-drying the concentrate completely inhibited the growth of staphylococci at a concentration of less than I mg./l. This spectacular potency was taken to suggest near-purity of the material, but later work showed it to be less than $2 \%$ pure.

The first parenteral administration to an animal was made on 19 March 1940, when Chain asked J. M. Barnes, who was at that time working on another project with mice, to give each of two mice an intraperitoneal injection of $40 \mathrm{mg}$. of a preparation in I ml. water; no ill effects were recorded (Stewart, 1965). This particular preparation was not made by solvent transfer, though practically all subsequent material was. During the next 6 weeks Florey made various pharmacological experiments. The preparation's low toxicity was confirmed by the tolerance of mice to a single intravenous injection of ro mg., and of young rats to repeated subcutaneous doses. Intra- 
venous injections into an anaesthetized cat had no effect on blood pressure or respiration. Human leucocytes remained actively motile in a $1 \mathrm{mg} . / \mathrm{ml}$. solution for at least $3 \mathrm{hr}$, and tissue cultures were unaffected. The activity of the material against staphylococci was not greatly dependent on inoculum size. Penicillin could be detected in the blood after subcutaneous injection and was rapidly excreted in the urine.

Would this highly active and apparently almost non-toxic antibacterial be effective in vivo? Florey started the first mouse protection experiment to examine this question on 25 May, a Saturday - an indication of the urgency he felt, since normally no one would dream of starting such an experiment at a week-end.

Eight mice were given a dose of $x 10$ million mouse-virulent streptococci intraperitoneally. One hour later two were given a single subcutaneous dose of $10 \mathrm{mg}$. of penicillin and two were given four doses of $5 \mathrm{mg}$. at approximately $2 \mathrm{hr}$ intervals, and a fifth similar dose after a further $4 \mathrm{hr}$.

All four control mice which had received no penicillin died between 13 and $16+\mathrm{hr}$ after infection, when the treated mice were all alive and well. The treated mice receiving the smaller dose died after 2 and 6 days, the other two surviving without sign of sickness. The unit for penicillin had not been adopted at that time, but the $25 \mathrm{mg}$. received by the surviving mice probably contained no more than a total of 200 units.

It is typical of Florey's drive that within $26 \mathrm{hr}$ of the beginning of this experimentlong before it was completed-plans had been laid for increased production of penicillin by all means possible. The first requirement was vessels for growing the fungus in stationary culture on layers of medium $I$ to $I \frac{1}{2} \mathrm{~cm}$. deep. The conical flasks available were wasteful of both incubator and autoclave space, and a variety of alternative containers were tried-bottles, trays, pie dishes, bed-pans, plain or varnished tins, etc. These were used for several months but it became clear that special culture vessels would have to be obtained, though in wartime Britain this presented difficulties. The obvious material for their construction, glass, was ruled out because the delivery time

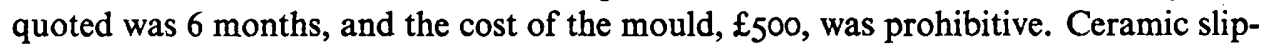
ware was then considered. It happened that Florey knew a consultant physician in Stoke-on-Trent, Dr J. P. Stock, to whom he wrote sending sketches of the kind of vessel required and asking which firms, if any, might be persuaded to produce them. Stock passed the sketches to James MacIntyre \& Co., Ltd. of Burslem and informed Florey by telegram. The following day Heatley went to Stoke, but his train was delayed and he was only able to visit the firm on the next day, 3 I October. He found that they had already made three (unfired) prototypes which the modeller was able to trim with the knife to a finally selected design. Three finished vessels arrived in Oxford on I 8 November, and the first main batch of 174 were ready, as promised, on 23 December. They were fetched by van that day, washed, charged and sterilized the next, and half of them were inoculated on Christmas Day 1940. These rectangular containers stacked well in autoclave and incubator. Each held $\mathrm{I} 1$. of medium in a layer $\mathrm{I} \cdot 7 \mathrm{~cm}$. deep, and hundreds of them were eventually obtained. They effectively solved the culture vessel problem.

The harvesting operation was next partly mechanized by a special trolley on which the rectangular vessels could be tilted so that their contents drained towards the spout. The medium was sucked out through a replaceable sterilized tube held in a 'changing pistol' which simultaneously delivered an excess of sterile filtered air into the vessel to take the place of the fluid removed. The vessels were then tilted backwards and I 1. quantities of replacement medium were added from bottles or tins. 
Extraction of the penicillin rapidly became a limiting factor in production. Initially, containers of culture fluid and solvent had been cooled in ice. With increase in scale they (and the operator) were cooled in the cold room. Discomfort led, after several unsuccessful attempts, to a workable but intricate extraction apparatus which could be used at room temperature.

The crude culture fluid, cooled in a worm surrounded by ice, was acidified with phosphoric acid immediately before being broken up into uniform droplets which fell slowly through a column of amyl acetate, giving up their penicillin to it, and passing to waste. The solvent slowly moved in a counter-current direction, penicillin-rich solvent being collected from the top of the column while fresh solvent was fed in at the bottom. Emulsion formation did not occur, but a gummy material collected at the bottom of the column and had to be removed periodically. Six such columns were mounted, with a warning bell, indicator lights, etc., on a stand made from a bookcase discarded from the Bodleian Library.

Its capacity was $\mathrm{I} 2 \mathrm{l}$. of fluid/hr, and it ran from January $\mathrm{I} 94 \mathrm{I}$ till it was superseded in the spring of 1942 by a much easier and more reliable system devised by Florey in which the cooled acidified culture fluid was deliberately emulsified with amyl acetate by means of a hand-operated disc-paddle, and the emulsion was then broken by passing it through a Sharples centrifuge. This principle was extended by A. G. Sanders, who designed, and with J. Kent built, two successive plants. The penicillin-rich amyl acetate leaving the Sharples centrifuge was collected and emulsified with a smaller volume of water to which sufficient sodium or barium hydroxide was added to keep it at a neutral $\mathrm{pH}$. The emulsion settled spontaneously, and the watery concentrate was put through another cycle with chloroform instead of amyl acetate. The final relatively small volume of mahogany-coloured watery penicillin concentrate was then worked up by hand. These entirely satisfactory plants, the first in the main building and the second, larger, version in what had been the post-mortem room in the Animal House of the Sir William Dunn School of Pathology, were remarkable for their motley components-milk churns, a milk cooler, a domestic bath, a bronze letter-box, cisterns, aquarium pumps and various taps and valves. The larger of the two processed about I60 1. of crude culture fluid in $3 \mathrm{hr}$, after which the gummy deposit in the centrifuge bowl had to be removed. It is remarkable that so much of the penicillin survived contact with the heavy metals in these plants. (When rectangular unvarnished tins were used as culture vessels excellent growth of the fungus was obtained repeatedly, but with each re-use the yield of penicillin fell to virtually nil after the fifth or sixth re-use.)

One item which fortunately was obtainable in quantity even in the most difficult war years was the I gal., thick, narrow-mouthed glass bottle closed with a stout metal screw-cap, as used for soft drink concentrates, etc. It was adopted as the standard container for the original extraction apparatus and for all harvesting operations, and modifications enabled it to be used for special purposes. Thus, for filtration, the metal cap was adapted to hold a Buchner funnel, suction being applied through a side tube. A similar bottle containing the fluid to be filtered was fitted with a bung carrying a wide tube. When inverted over the Buchner funnel the level of liquid in the latter automatically kept level with the open end of the wide tube till filtration was complete; since the bottles were the same size, the receiver did not overflow. Some of the bottles had a small hole drilled near the bottom and closed by a screw-operated cork pad which enabled them to be used as separating funnels; they were held inverted in a special stand, the lower layer being run out through a glass tap or some other controlling device 
mounted in a bung, while air was admitted through the small hole. A chain of operations, e.g. filtration followed by solvent extraction, could often be carried out without the pouring of material from one container to another, as would be done with conventional equipment.

Up to the end of 1940 the penicillin work had engaged the full time of one research worker and the part time, to varying degrees, of six others. No full-time technical help had been available, but at this time (early 1940) two trained technicians, G. A. Glister and S. A. Cresswell, were engaged for the culture and extraction work. Glister remained at the Dunn School for about 5 years, and when he left became Works Chemist of the Ministry of Supply penicillin factory at Speke. With their help a steady but still minute supply of penicillin became available, which enabled Florey to carry out more extensive mouse-protection experiments with different dosage schedules and up to 25 control and 25 treated mice. At least four more experiments were done with the same streptococcus, three with a staphylococcus, and two each with Streptococcus pneumoniae and Clostridium septicum; a good deal was learned from these experiments (Chain et al. 1940).

The mouse experiments were so promising that it was imperative to extend the trials to man. Since, in Florey's words, 'a man is 3000 times the size of a mouse', this required production greater by more than three orders of magnitude-the point at which, under normal conditions, the help of a commercial firm would be sought. But conditions were far from normal, with bombing by the Germans at its height and all firms more than fully engaged with Government contracts. After exploring the situation, Florey realized that there was nothing for it but to try to make penicillin on the required scale in the laboratory. Clearly, more technical help would be needed, but trained technicians could not be obtained. As an experiment two girls, both partly trained in nursing, were taken on temporarily in December 1940-the first female technical help ever to be employed in the Dunn School. They were Ruth Callow (sister of Chain's assistant, D. Callow) and Claire Inayat Khan. So successful was this innovation that more girls, Betty Cooke, Peggy Gardner, Megan Lankester and Pat McKegney, none of them trained technicians, were at different times taken on. These first 'penicillin girls', ably trained and organized by Glister, played an invaluable part in the production of penicillin for the first clinical trials. It is untrue that the entire resources of the Dunn School were given over to penicillin work. Apart from the technical assistance just mentioned, together with some from J. Kent, E. Vincent and D. Callow, the maximum research effort at any one time probably did not exceed the equivalent of four full-time research workers, and was most of the time less than this. Heatley noted in his diary on $3 \mathrm{r}$ December 1940 that the scale of production had been increased nearly Iooo-fold during the year.

On 27 January I94I C. M. Fletcher, who was a Nuffield Research Student of Registrar status at the Radcliffe Infirmary, Oxford, and maintained liaison between Florey and the hospital during the early clinical trials, cautiously gave an intravenous dose of $100 \mathrm{mg}$. of penicillin to a human volunteer. Although Io mg. of the same preparation had been without any apparent effect on a mouse, the patient suffered a delayed rigor. Was this due to penicillin itself or to an impurity? Some weeks previously Abraham had begun using chromatography on alumina as a means of purifying penicillin, and to everyone's immense relief one of his active fractions was found to be 
free from pyrogen when tested in rabbits by Florey. Chromatography was thereafter a routine step in production, the material being known at the time as 'therapeutic penicillin'; it typically had about 50 units/mg., though there was wide variation. Fletcher administered such material to a number of volunteers by various routes, and the resulting blood levels and urinary excretion of the drug were measured. In the light of these experiments, lasting about 2 weeks, Florey decided that continuous intravenous infusion was likely to be the most economical and efficient method of administration.

The first patient to be treated with penicillin parenterally was a desperately ill policeman, admitted to the Radcliffe Infirmary 2 months previously with suppurating abscesses resulting from a scratch on the face from a rose bush. He had lost one eye, one humerus was involved, and surgical drainage and treatment with sulphapyridine had not controlled the mixed streptococcal and staphylococcal infection. Penicillin, administered by intravenous drip from I 2 February, led within 4 days to a quite dramatic improvement, but supplies ran out and after holding his own for Io days the patient relapsed and died.

After this tantalizing result, further treatment of patients was delayed until a larger supply of the drug had been accumulated, but during the next 3 months five more patients were treated, four of them ill with serious infections. One of them suffered from an infected cavernous sinus thrombosis, a condition believed at the time to be invariably fatal; though he later died from ruptured mycotic aneurysm, healing of the infected sites was found to be well advanced. The case histories have been described in detail elsewhere (Abraham et al. 194I) and it must suffice to record here that the response to penicillin was considered almost miraculous. It seemed that penicillin had vast clinical potentialities, especially in time of war.

There was throughout the work at Oxford an extreme scarcity of penicillin, and it was for this reason that four of the first chosen six patients were children. All containers, including syringes, were rinsed out, and the urine from patients receiving the drug was jealously collected and the penicillin extracted from it. Probably the total production of penicillin up to the middle of I94I was of the order of 4 megaunits, of which half might have been used therapeutically.

Laboratory production could not be increased much more and, once he had good clinical evidence to present, Florey went to America (which was then not at war) under the auspices of the Rockefeller Foundation, with the object of trying to interest the Americans and persuade one or more commercial firms to prepare enough penicillin to treat a further score or more cases, which would have enabled its clinical value to be rigorously assessed. Without such additional proof it could hardly be expected that any firm would undertake large-scale production. It seems that Florey had approached the Rockefeller Foundation by the middle of April, if not earlier, and, the necessary formalities having been completed in secrecy, he and Heatley on 27 June I94I travelled in a blacked-out plane from Whitchurch, near Bristol, to an unknown airport, and thence to Lisbon. After 3 days of unaccustomed relaxation in this freely lit, non-rationed paradise, as it seemed, they proceeded to New York by Clipper, via the Azores and Bermuda. At the Rockefeller Foundation on Thursday, 3 July, Florey gave an account to Dr Alan Gregg of the results so far obtained with penicillin. Quiet and factual, the report was nevertheless intensely stimulating as to matter, while its mode of delivery was equally revealing of Florey's stature as a scientist.

Since likely contacts could not be pursued on Independence Day, Florey visited his 
friends, Dr and Mrs J. F. Fulton, at New Haven, Connecticut, where his two children had been staying. Fulton took Florey to Dr Ross Harrison, who recommended that he contact Dr Charles Thom, the mycologist. Florey saw Thom at Washington on 9 July, and was taken by him to Dr P. A. Wells of the U.S. Department of Agriculture, who suggested that the Department's Fermentation Division in the scarcely completed Northern Regional Research Laboratory at Peoria was the obvious place to seek expert help; he sent a telegram to Peoria asking that a cabinet of fermentation trays be put at Florey's disposal at once. Florey and Heatley reached Peoria on Monday, I4 July, and the Director, Dr E. O. May, and the head of the Fermentation Division, Dr R. D. Coghill, promised full co-operation. Heatley was to remain at Peoria, and started work at once with Dr A. J. Moyer. The lyophil-dried cultures brought from England germinated slowly and with difficulty, and it was at first feared that they might have died out at the high temperatures encountered since leaving England, over 2 weeks earlier. Since fresh yeast was not readily available, Moyer suggested that corn-steep liquor be tried, instead of yeast extract, since it was cheap, available, and already used as a source of growth factors in some fermentations. It not only accelerated growth of the penicillium, as did the English yeast extract, but increased the yield of the antibiotic; further increases were obtained when Moyer gradually adjusted the trace metal and carbohydrate composition of the medium. Shortly before Heatley left Peoria on 30 November I94I, having trained Mrs L. Robertson to carry out the penicillin assays, the yield had been raised from the I to $2 \mathrm{u}$./ml. commonly obtained at Oxford to $20 \mathrm{u}$. $/ \mathrm{ml}$. Later, the yield was vastly increased by improving cultural conditions and selecting better strains of the fungus. (For some years most commercial penicillin was obtained from a strain of Penicillium chrysogenum originally isolated from a mouldy cantaloupe in a Peoria market, or from substrains derived from it.)

Florey meanwhile was busy seeing people and firms in connexion with penicillin and other projects. He returned to Oxford in the middle of September 194I with the promise of the Chairman of the Committee for Medical Research of the U.S. Office of Scientific Research and Development that he would back the production of penicillin to his fullest power. One wonders whether this fateful assurance would have been so freely given had the Chairman, A. N. Richards, not known Florey's calibre from the time some 15 years previously when the two had collaborated in Richards's laboratory.

Florey has often been criticized for 'giving away to America' a project which might have earned this country millions of dollars. It is true that huge sums have been made from penicillin, but the criticism will not bear examination. In the first place the Oxford process for growing the fungus and extracting the penicillin only became commercially practicable when the yield had been greatly increased by the work at Peoria and elsewhere in America. It is doubtful whether useful patents could have been obtained in England in 1941, and there was no mechanism by which the University, for instance, could have assisted. Finally, when Florey sought high-level advice on the question he was told authoritatively that the patenting of a potentially beneficial medical discovery or invention was against medical ethics and from that point of view out of the question.

Those living and working in Oxford during the war had cause to be, and were, profoundly thankful that Oxford escaped the serious bombing suffered by some other parts of England at the time. To be sure, queueing for food, etc., wasted much time, but Civil Defence duties such a 'firewatching' could be put to use since those sleeping at 
the laboratory could-and did-work until a late hour. In the spring of I94I, when invasion of Britain was no longer unthinkable, some of those engaged in the work rubbed freely-sporing mycelium in their pockets; the hope was that if the Germans invaded, someone might escape to a neutral country and, recovering the fungus from their clothes, enable the work to continue.

On his return from America in September I94I Florey and his wife, Dr M. E. Florey, carried out a second series of clinical trials, which provided more precise information on dosage and methods of administration (Florey \& Florey, 1943). The penicillin for these trials was at first made mainly in the Dunn School, but by the beginning of 1942 small amounts were contributed by Imperial Chemical Industries, Ltd. From September of that year, for some months, Kemball, Bishop \& Co., a small east London firm making citric acid by fermentation, brought 150 to 200 gal. lots of formalinized crude penicillium culture fluid to Oxford in milk churns by lorry for extraction in the Oxford plant. Later, penicillin was also supplied by the Therapeutic Research Corporation.

With the prospect of increased production of the drug came the question whether it could be successfully used in the treatment of war wounds. In North Africa, preliminary treatment of 15 battle casualties had given moderately encouraging results (Pulvertaft, I943).

During the summer of 1943 (he was away from Oxford from 23 May to 2 September) Florey took part in an extensive investigation in North Africa, the purpose of which was to find out how best limited amounts of penicillin could be used to treat battle casualties, and at what point(s) in the army medical organization it could be most effectively used. The penicillin was provided from the four sources mentioned above, and because the supply was scanty and likely to be so for some time, the emphasis was on local, rather than systemic, administration, e.g. as a powder (mixed with sulphonamides) or in solution. A radical departure from established surgical practice was made, namely early suture of wounds, with penicillin irrigation through small indwelling tubes. This enabled healing to take place in a fraction of the time which would otherwise have been required, and with far better results. Florey, who insisted on remaining a civilian, and Brigadier Hugh Cairns submitted a I14-page preliminary report of this work jointly to the Medical Research Council and to the War Office. This report was published in October of the same year (Florey \& Cairns, 1943) and received high praise from Major-General Poole, Directory of Pathology, War Office.

By 1944 penicillin production was in the hands of commercial firms, while the Medical Research Council's Penicillin Clinical Trials Committee were handling this aspect. However, contributions were still made from Oxford laboratories, notably on its chemistry and, under Dr Dorothy Hodgkin, its crystallography. Florey continued to to supervise local clinical trials of various kinds and to work personally on biological aspects of penicillin and other antibiotics. He extracted and crystallized claviformin, and had a hand in the detection, extraction and assessment of several others, including helvolic acid, proactinomycin, mycophenolic acid, a colicine (later shown to be identical with colicine V), tardin, hirsutic acid, ayfivin (later known as bacitracin), cephalosporins $P_{I}$ and $N$, and micrococcin. The latter was isolated by T. L. Su from one of a large number of antibiotic-producing organisms he had obtained from Oxford sewage. It was not very soluble in aqueous media, nor was it toxic, but the growth of several strains of Mycobacterium tuberculosis was inhibited by one part in 100,000 or more. Quite large 
amounts could be injected in finely divided form into rabbits and mice without any apparent ill effect and were rapidly removed by the reticulo-endothelial system. Florey thought it worth investigating whether an antibacterial substance such as this, taken up by the phagocytic cells, might act upon intracellular tubercle bacilli which would by their position be protected from any soluble agent that could not cross the cell membrane; or might, at any rate, form a protective zone of 'fortified' phagocytes around a lesion. However, this concept, centred on what was termed by a colleague 'Florey's Fortified Phagocytes', was not fruitful with micrococcin, for a variety of possible reasons (Florey, 1954). Nevertheless, a good deal of quantitative information was obtained on the distribution of micrococcin among, and its persistence in, various organs of the body, and, qualitatively, in individual cells. It was still measurable in liver, spleen and kidney more than 6 months after a single intravenous injection.

As was to be expected, Florey received much correspondence from the lay public, some of it bizarre, e.g. a letter from Scotland drawing attention to a possible antibacterial effect of oat bran was accompanied by a raw herring, undeniably well preserved, packed in this material. The most fruitful contact, mediated by Dr C. S. Blyth Brook in 1948, was with Professor Guiseppe Brotzu, formerly Rector of the University of Cagliari, Sardinia, who unreservedly passed on to Florey an antibiotic-producing cephalosporium which he had isolated from the sea near a sewage outlet at Cagliari. This organism produced a range of antibiotics, and years of patient study by Abraham, the late G. G. F. Newton and others in Florey's department led to the discovery and characterization of the cephalosporins, perhaps the most interesting and important antibiotics to be discovered since the natural and semisynthetic penicillins.

The discovery of penicillin by Fleming - another original member of our Societyand its production and use are easily understood by the layman, and this, together with its amazing effect (now taken for granted) in certain diseases, led to many articles and items about it in the Press, even in children's magazines and books. 'Penicillin' has been set as a school 'project' on both sides of the Atlantic, and it, and antibiotics in general, have inspired a number of popular and semipopular books.

What was Florey's role in the development of penicillin as a chemotherapeutic agent? He himself pointed out on several occasions that he and Chain had extreme good luck in choosing penicillin as one of the first natural antibacterials to be studied in their programme; however, the programme was intended to be a wide one, and penicillin, though merely at that time a laboratory curiosity like the others, would inevitably have been one of the earliest to be studied.

Florey was once maliciously described as a physiologist who happened to have in his department the right people to work through the project. He would have been the first to disclaim expert knowledge in, for example, chemistry or bacteriology, but those who knew him know also what shrewd comments and suggestions he could make in fields other than his own. He repeatedly stressed that the outcome was the product of a team, and was scrupulous in giving all possible credit to the other members of it. But he had prepared the ground at Oxford by building up during previous years a laboratory intentionally staffed with workers trained in a variety of disciplines. This was a logical extension of his conviction-shared by few others when he came to Oxford in 1935 - that advances in medicine were most likely to spring from rigorous experiment in the basic medical sciences. 
At the purely practical level his own contributions were substantial and crucial. His firsthand experience of the pathological processes of inflammation, necrosis, the role of small blood vessels and so on, as well as his grasp of physiological principles, enabled him to plan the biological experiments on toxicity and pharmacological properties with economy and elegance. A colleague remarked of this phase that "not an experiment was wasted', and these early animal experiments provided a firm basis for planning human therapy. Without them, the results from the treatment of the first half-dozen human patients might well have been inconclusive instead of clear-cut, with who knows what frustration and delay in the introduction of penicillin into medicine.

Important as this work was, it is in his other role, as leader of the team, that Florey was irreplaceable. One remembers his humour, his infectious enthusiasm, and his genial and constructive cynicism. Certain decisions he made boldly and swiftly on his own initiative and responsibility; but in general he constantly consulted his colleagues and allowed them virtually complete freedom to pursue their own branch of the work as they thought best-or rather, as they thought best after discussion with him or with another colleague. There were few meetings of 'the team' as such, but many informal discussions with individuals or small groups enabled Florey constantly to reassess the course of the work and to suggest revisions of the immediate programme. In retrospect, though there were many disappointments and failures, there were few if any occasions when some remedy or alternative approach could not be suggested. How remarkably effective was his firm but unobtrusive leadership is shown by the fact that the first clinical trials were completed after no more than 18 months of sustained work.

N. G. HeAtLEY

\section{REFERENCES}

Abraham, E. P. (1970). Biographical Memoirs of Fellows of the Royal Society. (In preparation.)

Abraham, E. P., Chain, E., Fletcher, C. M., Florey, H. W., Gardner, A. D., Heatley, N. G. \& JenNINGS, M. A. (1941). Further observations on penicillin. Lancet ii, I77.

Chain, E., Florey, H. W., Gardner, A. D., Heatley, N. G., Jennings, M. A., Orr-Ewing, J. \& SANDERS, A. G. (1940). Penicillin as a chemotherapeutic agent. Lancet ii, 226.

Clutterbuck, P. W., Lovell, R. \& Raistrick, H. (1932). Studies in the biochemistry of microorganisms. XXVI. The formation from glucose by members of the Penicillium chrysogenum series of a pigment, an alkali-soluble protein, and penicillin-the antibacterial substance of Fleming. Biochemical Journal 26, 1907.

FALK, L. A. (1944). The history of penicillin. Journal of the American Medical Association 124, 1219.

FLOREY, H. W. (1954). The chemotherapy of tuberculosis. Tenth Listerian Oration. Canadian Medical Association Journal 71, 417.

Florey, H. W. \& CAIRNs, H. (1943). Penicillin. A Preliminary Report to the War Office and the Medical Research Council on Investigations Concerning the Use of Penicillin in War Wounds. War Office, A.M.D. 7.

Florey, H. W., Chain, E., Heatley, N. G., Jennings, M. A., Sanders, A. G., Abraham, E. P. \& Florey, M. E. (1949). Antibiotics. A Survey of Penicillin, Streptomycin, and Other Antimicrobial Substances from Fungi, Actinomycetes, Bacteria, and Plants. Oxford and London: Oxford University Press.

FLOREY, M. E. \& FlOREY, H. W. (1943). General and local administration of penicillin. Lancet i, 387 . GARDNER, A. D. (1940). Morphological effects of penicillin on bacteria. Nature, London 146, 837 .

GoldSWORTHY, N. E. \& FLOREY, H. W. (1930). Some properties of mucus, with special reference to its antibacterial functions. British Journal of Experimental Pathology II, 192.

Pulvertaft, R. J. V. (1943). Local therapy of war wounds. I. With penicillin. Lancet ii, 34I.

Stewart, G. T. (1965). The Penicillin Group of Drugs, p. 10. Amsterdam, London, New York: Elsevier. 